\title{
OS DIREITOS SOCIAIS À LUZ DA TEORIA DE JUSTIÇA DE AMARTYA SEN
}

\section{SOCIAL RIGHTS UNDER THE AEGIS OF AMARTYA SEN'S THEORY OF JUSTICE}

\section{Fernando Borba de Castro}

Universidade de Lisboa, Lisboa, Portugal

fernandoborb@hotmail.com

Palavras-chave: Amartya Sen; Direitos Humanos; Direitos Sociais; Capacidades; Justiça Social.

Keywords: Amartya Sen; Human Rights; Social Rights; Capabilities; Social Justice.

Resumo: Este estudo tem como objetivo apresentar e discutir os direitos sociais à luz da teoria de justiça de Amartya Sen. A abordagem das capacidades do economista indiano descortina uma perspectiva comprometida com o progresso das obrigações oriundas dos direitos humanos e imprescindíveis à produção de um Estado Constitucional Social. O foco nas necessidades das pessoas assoladas por privações nos permite avançar na investigação da natureza dos direitos sociais, assim como na questão de em que medida são direitos humanos e constitucionais. Relacionando-o a autores como Martha Nussbaum e Miguel Nogueira de Brito, estudamos o impacto da positivação dos direitos prestacionais nas Constituições e buscamos uma alternativa à sua concretização exclusivamente por intermédio de um processo de judicialização.

Abstract: The aim of this study is to exhibit and discuss social rights under the aegis of Amartya Sen's theory of justice. The Indian economist's approach of capabilities reveals a prospect committed to the progress of human rights obligations and essential to the production of a Social Constitutional State. Focusing on the needs of people beset by deprivation allows us to advance in the investigation of the nature of social rights, as well as in the extent to which they are human and constitutional rights. Relating it to authors such as Martha Nussbaum and Miguel Nogueira de Brito, we study the impact of the positivation of the benefit rights in the Constitutions and we look for an alternative to its concretization by means of a process exclusively of judicialization. 


\section{Introdução}

Com este estudo apresentaremos e discutiremos os direitos sociais à luz da teoria de justiça de Amartya Sen ${ }^{1}$. Exporemos as contribuições do autor à pesquisa acerca da natureza jusfundamental dos direitos sociais. Então, verificaremos de que maneira o horizonte propicia uma compreensão de tais direitos atenta à particularidade da sua conexão ao bem-estar social das comunidades políticas. Por fim, discutiremos se a teoria deixa pontos em aberto para evoluirmos na investigação da natureza e da efetividade dos direitos sociais.

A Declaração Universal de Direitos Humanos de 1948 é um marco no desenvolvimento de novos direitos. Afirma uma singular "geração» ou «dimensão» de prerrogativas², associadas não à limitação

1. Esta investigação adota como ponto parcial de partida algumas reflexões e debates suscitados no âmbito do programa de mestrado em Ciências Jurídico-Políticas da Faculdade de Direito da Universidade de Lisboa no ano letivo de 2017/2018. O núcleo da pesquisa foi apresentado na forma de relatório da unidade curricular de Ciência Política, com o título A justiça como capacidades humanas na teoria de Amartya Sen. Naturalmente, a investigação foi largamente remodelada e ampliada, notadamente através de abrangente atualização bibliográfica.

2. Em atenção à perspectiva da evolução dos direitos, é importante registrar que o emprego do termo «geração» é controverso no meio científico. Ingo Sarlet desponta entre os críticos da terminologia, preferindo adotar a palavra «dimensão». Segundo ele, a ideia de «dimensão», além de apontar para o caráter cumulativo do processo evolutivo e para a natureza complementar dos direitos fundamentais, expressa sua unidade e indivisibilidade no contexto do direito constitucional. A trajetória dos direitos envolve um processo de constante transformação, culminando com a recepção, tanto nos catálogos cons- do poder do Estado, mas à sua atuação positiva para promover a melhoria global nas condições de vida das pessoas. A concretização da dignidade humana requer a realização da igualdade entre os indivíduos, e a Declaração de 1948 evidencia o papel dos poderes públicos e da sociedade nesta tarefa.

Nesta seara, algumas democracias constitucionais do segundo pós-guerra positivaram prestações sociais em suas Cartas Magnas. É o que acontece, exemplificativamente, com a Constituição italiana de 1947, a portuguesa de 1976, a espanhola de 1978 e a brasileira de 1988. Então, a construção de um Estado Constitucional Social, alicerçado na dignidade humana, passa a ser um imperativo do direito, e não uma intenção de justiça desprovida de juridicidade.

Muitas privações de caráter econômico e social atingem a humanidade, especialmente países em desenvolvimento: a fome, a falta de cuidados médicos, a negação à educação, o labor em condições indignas ou sem uma remuneração que atenda às necessidades mais básicas das pessoas, explicitam graves problemas mundiais. À medida que a evolução do bem-estar social adquire, para além da desejabilidade política e social de suas metas, clara relevância jurídica, a atenção da investigação científica volta-se à efeti-

titucionais quanto na esfera do Direito Internacional, de múltiplas e variadas posições jurídicas, cujo conteúdo é variável, como as transformações ocorridas na realidade social, política, cultural e econômica ao longo dos tempos (Sarlet, 2007: 51-53). Concordamos com a ressalva ao termo «geração», preferindo a adoção da palavra «dimensão». Utilizamos ambos os termos neste estudo, mas não desconhecemos a divergência teórica descrita e tampouco os tratamos como se fossem sinônimos. 
vidade das normas que prescrevem a superação ou mitigação das incapacitações que assolam a condição humana.

Neste contexto, a teoria de justiça de Amartya Sen analisa os direitos sociais a partir da abordagem dos direitos humanos. Associa-os à expansão das liberdades e das oportunidades humanas, para que as pessoas possam realmente optar viver um dos diferentes tipos de vidas que estejam ao seu alcance. O horizonte proposto avança na investigação do papel do Estado e dos indivíduos no fortalecimento e na proteção dos direitos sociais.

Como é próprio da abordagem dos direitos humanos, destacaremos a interdisciplinariedade do estudo. Iniciaremos o estudo com a apresentação do problema da justiça social em sede de filosofia política, através das análises de obras de John Rawls e Ronald Dworkin. Todavia, desenvolveremos e discutiremos as questões suscitadas pela ideia de justiça de Amartya Sen com contribuições primordiais do direito constitucional e da teoria tanto política quanto jurídica, assim como de uma visão mais crítica da teoria dos direitos humanos.

\section{Metodologia}

Trata-se de investigação biblográfica e positiva cujo ponto de partida é a apresentação dos escritos sobre a justiça social em dois expoentes do que Amartya Sen designa de «institucionalismo transcendental»: os estadunidenses John Rawls e Ronald Dworkin.

Examinamos a questão da distribuição de recursos em uma comunidade política sensível à igualdade entre os cidadãos nas obras A Theory of Justice, Justice as Fair- ness e Political Liberalism, todas de John Rawls. Então, abordamos a filosofia política de Ronald Dworkin em Is Democracy Possible Here? Principles for a New Political Debate e Sovereign Virtue: The Theory and Practice of Equality, com foco em uma matéria que o autor denuncia que teria sido negligenciado por John Rawls.

Em seguida, exibimos o pensamento de Amartya Sen em The Idea of Justice e Development as Freedom. Identificamos as contribuições que extrai de John Rawls e Ronald Dworkin, mas também suas principais críticas.

Na exposição e análise do trabalho de Amartya Sen, tratamos primeiramente de questões gerais de sua visão acerca da justiça. Em um segundo momento, nos dedicamos em especial ao horizonte das vidas e capacidades humanas, intimamente associado aos direitos humanos, sobretudo àqueles mais vitais ao desenvolvimento de um Estado Consticional Social. Nos referimos, é claro, aos direitos sociais da pessoa humana.

Identificamos as luzes lançadas por Amartya Sen ao problema do que realmente significa afirmarmos que um cidadão possui direitos sociais, enquanto espécie de direitos humanos. A resposta implica consequências, tanto para a sociedade em geral quanto para as instituições políticas e indivíduos. Problematizando a matéria, estabelecemos um diálogo com as abordagens de Martha Nussbaum e Miguel Nogueira de Brito.

A teoria de Amartya Sen aperfeiçoa a compreensão dos direitos humanos sociais, mas observações de Martha Nussbaum, Miguel Nogueira de Brito e Joaquín Herrera Flores indicam pontos em que a investigação científica ainda pode evoluir. Discutimos em que medida os autores abrem 
espaço à evolução da pesquisa acerca do caráter jusfundamental dos direitos sociais e nos possibilita avançar na questão imperativa que é a sua efetividade.

Progredimos na busca da natureza, do regime e do significado dos direitos sociais. Dirigimos nossa atenção à vinculação entre direitos sociais, direitos humanos e direitos constitucionais, atentos à importância de uma teoria crítica dos direitos humanos. Ao estudar o impacto da positivação dos direitos prestacionais nas Constituições, buscamos caminhos à sua concretização, atualmente à mercê da esgotada judicialização do direito.

\section{Resultados}

A teoria de justiça de Amartya Sen dispensa cuidado especial aos direitos sociais. Ao relacioná-los à expansão das capacidades e liberdades dos seres humanos, no provoca a refletir a respeito das especificidades dos direitos associados ao bem-estar social (Sen, 2009: 500-501).

Ao contrário de John Rawls e Ronald Dworkin, Amartya Sen não se preocupa em descrever como seria a justiça em uma comunidade política perfeita. A definição de uma sociedade ideal, que realiza as exigências de certos princípios, é objeto de estudo do «institucionalismo transcendental». Ao conceber a justiça a partir de determinados princípios, as perspectivas de John Rawls e Ronald Dworkin são descritas como "centradas em arranjos», escolhidos através de acordos hipotéticos entre os membros de uma sociedade para perfazer a estrutura básica de uma comunidade (Sen, 2009: 101-102).

Amartya Sen propõe uma visão «focada em realizações». Defende ser primordial a consideração quanto ao comportamento que as pessoas efetivamente adotam no mundo real, ao invés de partirmos do pressuposto de que todos seguem o comportamento conforme o ideal. O professor indiano não é cético apenas em relação à convergência de comportamentos segundo o ideal: também duvida da plausibilidade de um acordo unânime em relação a um único conjunto de princípios de justiça a definir as instituições que devem governar a sociedade (Sen, 2009: 44).

Em John Rawls, por exemplo, nos deparamos com a ideia inicial de um acordo hipotético entre os membros de uma sociedade com o fim de prescrever os princípios regentes de instituições justas. Não temos um contrato social para a resolução da legitimidade do Estado e do controle de um poder despótico, mas preocupado com a distribuição de recursos entre os membros de uma comunidade política. As pessoas devem escolher princípios para governar a sociedade, sob um imaginário «véu da ignorância» ${ }^{3}$, que as im-

3. Em A Theory of Justice, John Rawls propõe a «posição original» como uma maneira de estabelecer um processo equitativo de escolha de princípios para reger a sociedade. Sua ideia é a adoção de uma justiça processual. O autor busca anular os efeitos das contingências específicas que conduzem as pessoas a oporem-se umas às outras e a cair na tentação de explorar circunstâncias naturais e sociais em seu benefício. Assim, situa os indivíduos ao abrigo de um «véu da ignorância». As pessoas desconhecem como uma série de alternativas afetarão suas situações concretas e são obrigadas a avaliar os princípios exclusivamente com base em considerações gerais. Em tal situação, as pessoas não conhecem o seu lugar na sociedade, a sua posição de classe ou seu estatuto social. Igualmente, desconhecem a fortuna ou distribuição de talentos naturais ou capacidades, a inteligência, a força etc. Também ignoram sua própria concepção de bem, os detalhes de seu projeto de vida ou mesmo as suas 
pede de conhecer uma série de variações que influenciarão suas condições na comunidade (Rawls, 1993: 121).

Para John Rawls, na "posição original» as partes deliberariam os seguintes princípios: i) cada pessoa deve ter um direito igual ao mais extenso sistema de liberdades idêntico para as outras («princípio da liberdade»); ii) as desigualdades econômicas e sociais devem ser distribuídas por forma a que, simultaneamente: a) resultem os maiores benefícios possíveis aos menos beneficiados ( princípio da diferença»); b) decorram de posições e funções às quais todos têm acesso ("princípio da justa igualdade de oportunidade») (Rawls, 1993: 54-57).

Apesar de considerar os princípios indisssociáveis, John Rawls é favorável a uma ordenação lexical entre eles. Isto significa a satisfação do primeiro princípio antes de se passar para o segundo, e a concretização do segundo antes do terceiro. 0 «princípio da liberdade» possui prioridade sobre os demais, somente sendo possível limitar uma liberdade básica com fundamento na proteção da mesma ou de outra(s) liberdade(s) básica(s). Já o «princípio da justa igualdade de oportunidade» tem preferência em relação ao «princípio da diferença». John Rawls atribui às pessoas preferências por aquilo que designa de «bens primários»: liberdades, oportunidades, rendimentos e bens (Rawls, 1993: 59-61).

O investigador classifica o «princípio da liberdade» antes daquele que regula as desigualdades econômicas e sociais. A es-

características psicológicas particulares. Destarte, as pessoas devem escolher os princípios cujas consequências estejam dispostas a viver, inclusive independentemente da geração a que pertençam (Rawls, 1993: 121-123). trutura básica da sociedade deve realizar a distribuição das desigualdades de rendimentos e poder por formas que sejam consistentes às iguais liberdades exigidas pelo princípio antecedente. Uma sociedade só é justa se aceita os três princípios. Os três devem ser tratados e resolvidos, mas tal processo acontece em termos e com exigências distintas (Rawls, 1993: 63-65).

Somente o «princípio da liberdade» é consagrado na Carta Constitucional, através da convenção constituinte, após a fase do contrato social hipotético. O referido princípio exprime o mínimo de existência. Cabe à «fase legislativa», expressa pela Assembleia Legislativa, depois da convenção constituinte, a abordagem das privações econômicas e sociais para além do mínimo (Rawls, 1993: 56-57).

O princípio rawlsiano da «diferença» tolera uma desigualdade caso gere evolução na condição de todos, particularmente dos menos favorecidos. Trata-se de uma maneira de tratar a justiça social no plano constitucional. Ele descortina prestações do Estado correspondentes a direitos distintos daquelas tradicionais prerrogativas de proteção do indivíduo em face do Estado. Medidas como a concessão de um mínimo social que abranja as necessidades básicas das pessoas, a instituição de imposto sobre o consumo a uma taxa marginal contínua e a tributação de heranças são exemplos de políticas que poderiam melhorar a condição dos mais desfavorecidos (Rawls, 2001: 46-48).

Por sua vez, Ronald Dworkin teoriza, a partir de John Rawls, a justiça distributiva por intermédio de um sistema compensatório atento às capacidades desiguais e à sorte das pessoas. Acredita que os governos, ao compreenderem que cada vida 
humana possui valor objetivo especial e que cada indivíduo é responsável pela realização de sua própria vida, devem respeitar e tratar todas as pessoas com igual preocupação. Tal requer instituições que mirem também a realização da igualdade econômica, compreendida como igualdade de recursos, sensível às escolhas pessoais (Dworkin, 2006: 09-11).

A distribuição igualitária de recursos em uma comunidade política não deve atribuir a todos um mesmo montante, mas uma soma que impeça a inveja entre as pessoas. Não satisfaz o que o autor designa de «teste da cobiça» uma sociedade em que há pessoas que preferem os recursos umas das outras, assim como o padrão de consumo e trabalho que os origina. Vejamos: ainda que provida de menos recursos, uma pessoa com finalidades e desejos mais simples se comparada à outra, atinge mais facilmente um estado de bem-estar do que a segunda com o mesmo quinhão (Dworkin, 2006: 63-65).

Acontece que a solução do problema não pode ser obtida mediante uma distribuição mecânica de recursos. 0 «teste da cobiça» envolve a questão das desigualdades entre os indivíduos em seus recursos pessoais e também na má-sorte. As distintas capacidades físicas e mentais, a exemplo de talentos e enfermidades, ilustram a disparidade entre recursos pessoais. Já riscos que não podem ser previstos exprimem a pura sorte (correspondentes aos recursos impessoais) (Dworkin, 2009: 79-80).

Ronald Dworkin teoriza a situação de um grupo de náufragos em uma ilha deserta provida de recursos vastos que realiza um leilão. São distribuídos recursos impessoais e pessoais, incluindo a venda deapólices deseguros contra adversidades não oriundas de escolhas individuais, a exemplo de doenças e acidentes. $\mathrm{O}$ autor enfatiza a responsabilidade pessoal, ponto que considera ter sido negligenciado pelo "princípio da diferença» de John Rawls. Defende distinguir a condição daqueles que se encontram em carência em razão de doenças ou má sorte daqueles que se encontram assim em virtude da opção por não laborar (Dworkin, 2006: 103-104).

Sua proposta é diferenciar também a personalidade do indivíduo de seus recursos pessoais. Enquanto a primeira envolve as convicções, gostos, motivações e expirações, o segundo abrange saúde, força e talento. A comunidade política deve ter como aspiração eliminar ou atenuar as diferenças entre os indivíduos e seus recursos pessoais, agindo para melhorar, por exemplo, as condições dos deficientes físicos ou incapazes de auferir rendimento satisfatório. Rejeita, todavia, que a sociedade intervenha para aliviar as diferenças baseadas na personalidade (Dworkin, 2005: 400-401).

O mercado hipotético de seguros idealizado por Ronald Dworkin trata a questão da justiça distributiva levando em consideração as desigualdades nas capacidades físicas e mentais das pessoas. Alguém que nasce com deficiência, por exemplo, devido aos altos custos de tratamentos, encara a vida com menos recursos. Tal circunstância justifica uma compensação, em um esquema dedicado à igualdade de recursos. Para o autor estadunidense, o mercado de seguros, embora não restabeleça o equilíbrio, já que nada pode fazê-lo, procura atenuar um aspecto da injustiça (Dworkin, 2006: 101).

Amartya Sen rejeita a abordagem dworkiana da justiça distributiva. Além da censura à operação de faz-de-conta 
que considera ser típica da justiça transcendental, critica que o pensamento não abrange desvantagens de capacidades não oriundas de características ambientais. Embora a perspectiva de Ronald Dworkin leve em consideração as variações nas condições pessoais, não é certo, para o pesquisador indiano, que os mercados de seguro consigam transacionar contra adversidades relacionais e ambientais (Sen, 2009: 158-164).

Ronald Dworkin admite a intervenção do Estado através de prestações para corrigir desigualdades que não tenham origem na responsabilidade individual (Dworkin, 2005: 394-395). A sensibilidade às variações das capacidades humanas de acordo com características físicas e mentais é um ponto de diálogo com Amartya Sen. O economista indiano, no entanto, amplia o alcance dos fatores que ocasionam capacidades desiguais. Como ponto de partida, Amartya Sen não envereda pela proposição de qualquer espécie de acordo, identificação de arranjos ideais ou teorização de esquemas imaginários. Busca afastar-se do que considera ser uma operação fictícia própria da justiça transcendental. Pretende, ao contrário, provocar ações que conduzam a mudanças concretas nas vidas humanas assoladas por injustiças (Sen, 2009: 103-104).

Nos deparamos com uma abertura da ideia de justiça. Sua atenção se volta ao que é preciso fazer para produzir resultados mais justos nas vidas e liberdades das pessoas. As preocupações e considerações para a formação da sua teoria de justiça são plurais, e, por vezes, como o mesmo reconhece, até conflitantes (Sen, 2009: 105).

O pesquisador não põe em causa a importância das instituições. Elas consti- tuem parte das realizações sociais almejadas pela sociedade. Entretanto, objeta que sejam encaradas como a totalidade do objeto da justiça (Sen, 2009: 134).

As vidas de todas as pessoas estão envolvidas na justiça. Enquanto uma justiça transcendental contenta-se com o estabelecimento de princípios que regem instituições justas, a exemplo daqueles preconizados por John Rawls, Amartya Sen refuta que as instituições possam ser boas em si mesmas, dissociadas dos meios possivelmente eficazes relativos à produção de realizações sociais aceitáveis ou até excelentes (Sen, 2009: 135).

o pesquisador dialoga profundamente com as teorias "centradas em arranjos» de John Rawls e Ronald Dworkin. Delas extrai lições positivas e decisivas, especialmente do primeiro, considerado por Amartya Sen o principal filósofo político de nosso tempo (Sen, 2009: 134).

O vencedor do Nobel de Economia de 1998 concorda, em geral, com a prioridade à liberdade atribuída por John Rawls. Considera valioso o pensamento rawlsiano no sentido da liberdade como uma preocupação central para a independência das pessoas e que diz respeito aos aspectos mais particulares da vida pessoal. John Rawls reconhece, segundo Amartya Sen, a importância da liberdade humana no sentido de dar às pessoas uma real oportunidade para fazerem o que desejarem de suas vidas (Sen, 2009: 110-111).

O investigador aceita também a prioridade fundacional que John Rawls fornece à equidade no desenvolvimento de uma teoria da justiça. Une-se ao filósofo político estadunidense na defesa da importância da pretensão de evitar qualquer parcialidade nas valorações. A justiça como equidade, segundo Amartya Sen, 
pode ser vista como uma exigência de imparcialidade, presente em John Rawls na teorização da «posição original». Para o autor, a teoria de John Rawls leva em consideração os interesses e as preocupações das demais pessoas, assim como a essencialidade de evitar a influência dos próprios interesses, prioridades pessoais, excentricidades ou preconceitos (Sen, 2009: 110-111).

Amartya Sen não põe em causa ainda que o princípio rawlsiano da "diferença» expõe a importância da equidade para os arranjos sociais. Acredita que o referido princípio permite deslocar o foco de atenção às provações que atingem aqueles que se encontram em piores condições. O professor indiano endossa a preocupação de John Rawls com a extirpação da pobreza, medida como privação de «bens primários». Amartya Sen reconhece a importância da teoria rawlsiana na análise de políticas públicas destinadas à eliminação da miséria (Sen, 2009: 112).

O pensador pretende ir além de John Rawls e das teorias contratualistas da justiça social. Amplia a ideia de justiça, recebendo influência de ensinamentos budistas e da tradição filosófica oriental. De lições de Gautama Buddha e de sua inquietação em relação às privações e inseguranças da vida humana, extrai que nasce uma certa responsabilidade para com os demais em situações de desigualdades marcadas por assimetrias de poder. Acredita em uma base solidária para a interação e atitudes humanas (Sen, 2009: 343).

Segundo o autor, Buddha propõe a visão de obrigação vinculada ao poder, existindo, por exemplo, uma responsabilidade para com os animais que surge da assimetria existente, e não de qualquer sime- tria que provoque a necessidade de cooperação. De forma semelhante, uma mãe tem uma responsabilidade para com um filho não porque o deu à luz, mas porque pode fazer por ele certas coisas que influenciarão sua vida e que ele próprio não consegue fazer (Sen, 2009: 287).

Valendo-se das lições budistas aludidas, Amartya Sen aduz que se alguém possui o poder de mudar algo e se, além disso, compreende que essa mudança irá reduzir a injustiça presente no mundo, há uma forte razão social para que assim aja. É o que chama de «obrigação associada a um poder eficaz», e que diferencia-se de uma mútua obrigação de cooperação. Defende que as pessoas não são apenas pacientes cujas necessidades merecem consideração, mas também agentes cuja liberdade de decidir o que se há-de valorizar, e como se há-de perseguir o que se valoriza, pode ir muito além dos interesses e necessidades próprios (Sen, 2009: 242).

Segundo o pensador, no mundo em que vivemos há um misto de lacunas institucionais e de comportamentos inadequados. É importante produzirmos instituições aqui e agora, para que se torne viável o progresso da justiça através do reforço das liberdades, das garantias e do bem-estar das pessoas que hoje estão vivas e que amanhã desaparecerão. Exigir hoje do comportamento humano mais do que se pode cumprir no futuro não fará com que a causa da justiça logre êxito significativo (Sen, 2009: 132-133).

Amartya Sen volta sua atenção para questões concretas em termos não institucionais, refletindo acerca de alterações sociais aptas a produzir resultados mais justos. Ao longo da obra The Idea of Justice, recorre a uma situação hipotética para defender a centralidade das realizações e 
uma perspectiva que designa de «comparacional». Trata-se de indagar qual das seguintes crianças deve assenhorar-se de uma flauta: Ana, Bernardo ou Carla. Ana é a única que sabe tocá-la. Bernardo é muito pobre e o único dos três que não possui quaisquer brinquedos. Carla, por sua vez, trabalhou com afinco para construir a flauta com suas próprias mãos (Sen, 2009: 51-52).

Pode existir, no caso, uma solução justa dentro da perspectiva adoptada por utilitaristas, igualitaristas econômicos ou libertários, por exemplo, todas elas argumentadas. No entanto, é possível que não exista um arranjo social perfeitamente justo e identificável, em torno do qual possa emergir um acordo obtido de maneira imparcial. Isso significa que as soluções defendidas pelas distintas visões podem não prevalecer em todos os casos (Sen, 2009: 55-56).

Vejamos. A pretensão de Ana baseia-se na relevância da realização e felicidades próprias. A de Bernardo, na importância da equidade econômica. Por fim, a de Clara, no valor de se poder usufruir dos frutos do próprio trabalho. Em que pese o fato de ser possível tomar partido de alguma posição, os argumentos justificativos sobre que se apoiam cada uma das pretensões podem assumir uma forma imparcial (Sen, 2009: 58).

Assim, de um escrutínio exauriente, o pesquisador defende que é possível que exista uma pluralidade de razões robustas e imparciais. Como consequencia, acredita que ao depararmo-nos com diferentes tipos de razões de justiça concorrentes, poderá ser impraticável a identificação de um único conjunto de princípios complementares e coerentes, plenamente articulados entre si (Sen, 2009: 88).
Amartya Sen recusa uma teoria de justiça transcendental pois considera que demanda um salto em altura da perfeição que não ocorre no mundo real. Faria as vezes de uma manual revolucionário que ensinasse a fazer as coisas de uma só vez (Sen, 2009: 94).

Sua proposta é responder como reduzir as muitas e diversificadas injustiças que se verificam no mundo. O diagnóstico de situações injustas não requer uma única identificação do que significa uma sociedade justa. Um diagnóstico homogêneo do que é defectivo em uma sociedade (como caréstias, privação de cuidades médicos, grande índice de analfabetismo etc) pode compatibilizar-se com detecções diversificadas acerca dos arranjos sociais perfeitamente justos quanto a outros aspectos (Sen, 2009: 157).

A identificação do melhor de todos os arranjos não apenas não diz muito sobre o complexo da graduação na sua integralidade; também não determina uma escala única de graduação em cujo topo se eleva esse arranjo. Para tornar mais claro, o pesquisador utiliza o exemplo de que o fato de uma pessoa considerar a Mona Lisa o melhor quadro do mundo é silente em relação a como ela poderia graduar um Picasso se comparado a um Van Gogh. Assim, considera que a justiça transcendental não revela muito sobre os méritos comparativos de diferentes arranjos societários. (Sen, 2009: 54).

Amartya Sen dispensa unanimidade em matéria de justiça. Enxerga a possibilidade de acordos sobre particulares passos tendendes à ampliação da justiça como uma matéria-prima suficiente para conduzir à ação pública, sendo prescindível uma concordância sobre a natureza de uma sociedade perfeitamente justa. Acre- 
dita que a causa da justiça pode conviver com uma boa dose de incompletude ou de conflitos não resolvidos (Sen, 2009: 198-199).

A indagação acerca do que é uma sociedade justa não apenas não constitui um bom ponto de partida para a elaboração de uma teoria de justiça útil, como também não pode ser um ponto de chegada plausível. Haveria um hiato entre uma perspectiva relacional de justiça, conforme defendida por Amartya Sen, e uma transcendental (Sen, 2009: 54-55)

Em Development as Freedom, Amartya Sen defende que a expansão das liberdades das pessoas é o principal meio e o principal fim do desenvolvimento. Os indivíduos são compreendidos como agentes ativos de transformação, e não como simples recebedores de benefícios. Assim, é favorável a que sejam propiciadas oportunidades às pessoas. $O$ Estado e a sociedade possuem papéis amplos no fortalecimento e na proteção das capacidades humanas. Papéis de sustenção, e não de mera entrega sob encomenda (Sen, 2000: 71).

A imprescindibilidade de que as pessoas disponham de liberdade de determinação do tipo de vida que desejam viver é marcante na sua teoria. Orientada no sentido da liberdade e das oportunidades, a capacidade é compreendida como a verdadeira aptidão que as pessoas têm de optar viver um dos distintos tipos de vidas que estejam ao seu alcance (Sen, 2009: 313).

A pobreza, por exemplo, é uma forma de privação de capacidade, variável de acordo com condições pessoais, ambientais e sociais. Em um mundo repleto de privações e profunda desigualdade social, muitas vidas humanas são afetadas, e em direção a elas é que deve se voltar a atenção da justiça (Sen, 2009: 346-347).

Devemos desviar a atenção dos meios que servem para a vida e se concentrar sobre as oportunidades reais de vida. Os meios para uma vida humana satisfatória não são, em si mesmos, os fins próprios da vida com qualidade. Segundo Amartya Sen, John Rawls centra sua teoria de justiça nos meios, sem elucidar como os «bens primários» (os meios de caráter geral aptos a permitir alcançar os fins, como os rendimentos e riqueza, os poderes e as prerrogativas ligadas aos cargos, as bases sociais do respeito próprio etc) se concretizam em vida plena para as pessoas (Sen, 2009: 354-355).

Amartya Sen critica que o princípio rawlsiano da "diferença» ignora o desafio de converter os «bens primários» em uma vida boa. A conversão dos «bens primários» em capacidade para que as pessoas realmente façam aquilo que estimam pode variar significativamente de acordo com diferentes características inatas de cada indivíduo (a exemplo da propensão a alguma doença hereditária ) e de traços adquiridos que sejam distintos ou com efeitos divergentes produzidos pela diversidade do ambiente circundante (como viver em um local sujeito a doenças infecciosas endêmicas) (Sen, 2009: 347-348).

Embora John Rawls se concentre nos mais desfavorecidos, Amartya Sen acredita que a maneira como lida com a questão tem um alcance insuficiente. Critica a atenção dispensada pelo estadunidense às privações apenas na «fase legislativa», ou seja, depois que a estrutura institucional básica da sociedade já está montada segundo a «fase constitucional» (Sen, 2009: 354-355). 
Causa inquietação ao autor indiano que a natureza das instituições não seja influenciada pelas necessidades das pessoas assoladas por incapacitações. Acredita que John Rawls descarrega exclusivamente nos ombros dos frágeis ombros dos «bens primários» a determinação de instituições justas para fins de equidade distributiva (Sen, 2009, 356).

A conversão de «bens primários» em qualidade de vida, todavia, não pode ser relegada a segundo plano, e apenas discutida posteriormente. O foco de Amartya Sen é partir dos «bens primários» para chegar às capacidades. Julga que a liberdade possui um lugar que vai muito além do mero reconhecimento como parte das vantagens pessoais (rendimentos e riqueza). Contrariamente, aposta no papel das liberdades substantivas na sua forma de capacidade (Sen, 2009: 403).

Para Flávio Pansieri, o distanciamento entre Amartya Sen e John Rawls evidencia somente duas maneiras diferentes de se analisar como fazer justiça no Estado contemporâneo. A fronteira entre o justo e o injusto é objeto de questionamento de todos aqueles que se dedicam a pensar a vida em coletividade. As teorias de Amartya Sen e John Rawls contribuem, de formas distintas, para evoluirmos em relação aos desafios assumidos pelo Estado de direito democrático no século XXI, sendo certo que o tema da justiça permanecerá produzindo indagações (Pansieri, 2016: 204).

Solange Regina Marin e André Marzulo Quintana propõem que a abordagem das capacidades de Amartya Sen pode ser compreendida como uma extensão do pensamento rawlsiano a respeito do bem-estar. Amartya Sen, assim como John Rawls, enaltece uma via participativa e deliberativa para um acordo sobre a justiça, mas o primeiro parece complementar a teoria do segundo ao destacar a participação política das pessoas no processo de escolha social. No "véu da ignorância» de John Rawls, há a possibilidade de participação pública, mas prevalecem princípios particulares de justiça escolhidos a priori. Já Amartya Sen patrocina a participação pública através da discussão crítica de princípios conflitantes de justiça que possam coexistir e que serão escrutinados por indivíduos críticos e comprometidos, e não por indivíduos racionais do tipo homo economicus (Marin e Quintana, 2012: 529-528).

O Nobel de economia de 1998 defende as capacidades relacionando-as aos direitos sociais e partindo do horizonte dos direitos humanos. Critica que teorias como as de Ronald Dworkin e John Rawls se concentram demasiadamente nos bens, sem demonstrar como convertê-los em uma boa vida e sem lidar com uma série de variações que impactam a liberdade. A proposta de Amartya Sen é realizar a justiça social de forma concreta (Sen, 2009: 321-322).

O autor compreende os direitos humanos como exigências éticas dotadas de efetivo significado, ainda que não sejam especificados nas Constituições ou nas leis. Tais exigências são dirigidas ao Estado e a todas as pessoas. Embora a ausência de normas explícitas possa isentar a humanidade de responsabilidades legais pela realização dos direitos humanos, entre eles os sociais, não o faz em relação ao domínio ético. Os direitos sociais são concebidos como necessários ao progresso das vidas e das capacidades. São exemplos relacionados pelo autor o direito ao trabalho, à saúde, à educação, ao em- 
prego, à remuneração justa, entre outros (Sen, 2009: 504-505).

O fato de que as obrigações decorrentes do direitos humanos sociais possam algumas vezes se apresentar de modo impreciso não faz com que Amartya Sen tolere que possam ser consideradas inexistentes ou negligenciáveis. Os direitos sociais, enquanto direitos humanos, acarretam efetivas obrigações no domínio ético que, de um modo geral, recaem sobre todos quantos estejam em posição de ajudar (Sen, 2009: 492).

O avanço das exigências globais da justiça em muito se associa às obrigações oriundas dos direitos humanos, especialmente daqueles direitos mais preciosos à expansão das capacidades e que são imprescindíveis à produção de um Estado Social. Os direitos humanos, em síntese, derivam simplesmente da condição humana ou pertencimento à vasta categoria de seres humanos, sendo irrelevantes as particulares diferenças, grupos, seitas etc. Assim, não apenas não podem depender da cidadania ou nacionalidade, como não podem ser institucionalmente dependentes de um contrato social obtido em cada comunidade política (Sen, 2009: 208-209).

O significado ético dos direitos sociais enquanto direitos humanos cria pressões ou colabora para alterações sociais, quando não nas próprias instituições. Tais objetivos podem ser alcançados através de agitação ou elaboração de nova legislação, mas também mediante a criação de uma maior consciência da gravidade do problema (Sen, 2009: 481-482). A atuação legislativa por vezes constitui o caminho mais adequado para o progresso social, mas a monitorização social e outros tipos de apoios ativistas também podem con- tribuir com transformações. As atividades de organizações como a Human Rights Watch, a Anistia Internacional, o Comitê de Oxford de Ajuda contra a Fome, os Médicos Sem Fronteiras e a Cruz VermeIha explicitam caminhos para além da estrada legislativa. Além de haver diversas maneiras de promover os direitos humanos sociais, existe uma significativa complementariedade entre as diferentes vias (Sen, 2009: 481-483).

A teoria de Amartya Sen lança luz ao papel dos direitos sociais na construção de uma sociedade mais justa, mas comporta algumas críticas e é suscetível de aperfeiçoamento. Martha Nussbaum, por exemplo, considera que o pensamento de Amartya Sen, embora sugira algumas óbvias direções para políticas públicas, faz pouca referência ao direito e à estrutura institucional democrática. Assim, procura progredir na abordagem das capacidades. Focada na questão de uma justiça social mínima, propõe a conexão das capacidades à parte da Constituição de uma comunidade que prevê os direitos fundamentais de seus cidadãos. Afinal, muitas nações enumeram direitos de uma maneira a associá-los à ideia de vida compatível com a dignidade humana (Nussbaum, 2011: 69-71).

Gerald Allan Cohen acredita que Amartya Sen não pinta qualquer imagem do arranjo social inteiro que ele gostaria de ver ou tampouco nos diz como alcançar sua proposta. O foco de Amartya Sen, na teoria e na prática, se dirige aos males concretos. Sua preocupação é com a pobreza e a fome, sendo possível aduzir, como crítica ao autor indiano, que pouco tem a dizer a respeito do que deveríamos efetivamente fazer para aliviá-las (Cohen, 1993: 2160). 
Em um horizonte crítico, Joaquín Herrera Flores adverte que é primordial a construção de uma ordem política e social justa para a satisfação real, e não meramente ideal, dos direitos. Na maioria das ocasiões, as estruturas econômicas, políticas, culturais e sociais escondem gravíssimas violações dos direitos humanos. Direitos reconhecidos em declarações como a de 1948 somente poderão ser concretizados diante da instauração de uma estrutura social que permita o desenvolvimento dos países e da criação de condições de possibilidades para a decolagem econômica dos países empobrecidos ou a redistribuição da riqueza nos países desenvolvidos (Flores, 2009: 96).

\section{Discussão}

São muitas as privações de caráter econômico e social que assolam a humanidade. A teoria apresentada por Amartya Sen auxilia o progresso da ideia de justiça, mas também comporta objeções e aprimoramentos, especialmente no que tange à natureza jusfundamental dos direitos sociais, questão que procuramos associar à busca pela sua efetividade.

A Declaração Universal de Direitos Humanos de 1948 salienta a primordialidade do esforço por direitos que requerem a atuação positiva do Estado na promoção de melhores condições de vida de todas as pessoas do planeta (direitos de segunda "geração» ou «dimensão»). Os direitos sociais figuram entre as prerrogativas que dependem de uma prestação estatal e visam corrigir distorções nas condições assimétricas existentes entre os membros das comunidades políticas, sobretudo daquelas mais empobrecidas.
Paulo Bonavides nos dá conta que os «direitos de primeira geração» são os direitos de liberdade, geralmente os primeiros a constarem do instrumento normativo constitucional, a saber: os direitos civis e políticos. Eles correspondem, em grande parte, por um prisma histórico, à fase inaugural do constitucionalismo do Ocidente. Os «direitos de primeira geração» têm por titular o indivíduo, são oponíveis ao Estado, refletem faculdades ou atributos da pessoa e a subjetividade é seu traço mais marcante. Já os «direitos de segunda geração» são os direitos sociais, culturais e econômicos, bem como os direitos coletivos ou das coletividades. Foram introduzidos no constitucionalismo das diferentes formas do Estado Social, depois da germinação fruto da ideologia e da reflexão antiliberal do século XX. Nasceram abraçados ao princípio da igualdade (Bonavides, 2011: 516-518).

Com a declaração de direitos prestacionais, a eliminação da pobreza e de outras privações humanas de caráter econômico e social ganham destaque no palco dos esforços globais relativos aos direitos humanos. Constituições como a italiana de 1947, a portuguesa de 1976, a espanhola de 1978 e a brasileira de 1988 positivaram em seus textos os direitos sociais e a dignidade humana como valor das democracias constitucionais. Concretizar os direitos sociais, entretanto, é um desafio social, político e jurídico não resolvido apenas pela sua inserção em declarações de direitos ou Cartas Constitucionais.

Martha Nussbaum propõe que a abordagem das capacidades abrange a área ocupada tanto pelos «direitos de primeira geração» como pelos «direitos de segunda geração». Desempenha um papel 
correlato, fornecendo uma explicação de extrema importância acerca dos direitos fundamentais que pode ser adotada como base tanto para o pensamento constitucional no interior de uma nação como para refletir a justiça global. Além disso, torna clara a ideia de direitos fundamentais, demonstrando que as capacidades humanas centrais não são meras metas sociais desejáveis, mas direitos urgentes fundamentados na justiça (Nussbaum, 2006: 289-290).

Assim como a abordagem dos direitos humanos, o horizonte das capacidades consiste em uma explicação parcial da justiça social. A autora concebe um patamar mínimo a ser alcançado pela comunidade mundial. Como a perspectiva dos direitos humanos, a das capacidades insiste que cada ser humano possui direitos a essas importantes metas, e atribui à humanidade o dever de realizá-las (Nussbaum, 2006: 294).

Também na esteira dos direitos humanos, a visão das capacidades é, de certa maneira, centrada nas nações, segundo Martha Nussbaum, recomendando as capacidades como critérios de justiça social internamente para cada sociedade, como uma conta de direitos constitucionais básicos. Porém, a abordagem das capacidades fornece, como os documentos de direitos humanos, objetivos para a comunidade internacional e para a humanidade como um todo. Assim, requer um empenhamento conjunto dos Estados e da comunidade global (Nussbaum, 2006: 296).

Para Jorge Reis Novais, os direitos fundamentais não se restringem à liberdade e à propriedade. Garantem juridicamente, de modo mais abrangente, o acesso individual a bens que, pela sua importância para a dignidade humana, o aperfeiçoa- mento da personalidade, a autonomia, a liberdade e o bem-estar, a Constituição forneceu proteção máxima e estável. Neste contexto, o Estado Social não basta com a garantia e proteção da liberdade e da propriedade de um pequeno grupo provido de recursos, habilitação e educação para buscar, por si mesmos, as condições de uma existência digna. O Estado Social deve ser provedor de todas as pessoas que vivem sob sua jurisdição e que, abandonadas às próprias capacidades e ao jogo do livre mercado, seriam incapazes de aceder às condições mínimas de existência e, consequentemente, de gozo da liberdade e de desenvolvimento da autonomia pessoal (Novais, 2017: 309).

A expansão da ideia de justiça de Amartya Sen é muito importante, uma vez que, sem relegar a importância das instituições, não restringe o avanço da justiça social à criação de novas leis. O horizonte do economista indiano revela uma pluralidade de ações, que podem ou não envolver o Estado e a elaboração legislativa.

Em que pese o fato de a perspectiva de Amartya Sen nos convidar a descortinar a expansão das capacidades humanas não exclusivamente por intermédio da via legislativa, a compreensão da fundamentalidade e normatividade dos direitos sociais é um marco no estudo do Direito Constitucional que merece registro. A limitação dos recursos públicos ou a ausência de garantias fornecidas por instrumentos processuais típicos dos direitos de liberdade, que ao longo da história provocaram uma contestação da normatividade ou eficácia dos direitos sociais ${ }^{4}$, são obstáculos que

4. Paulo Bonavides observa que os direitos sociais primeiro passaram por um período de baixa normatividade ou tiveram a eficácia contestada, em consequencia da sua natureza exigir determinadas prestações materiais do Estado, nem sem- 
restringem a sua concretização prática, mas não fazem ruir sua plausibilidade. A difusão da verossimilhança dos direitos sociais é um importante passo que contribui para o avanço dos imperativos da justiça social no mundo, na medida em que é reconhecida sua juridicidade.

$\mathrm{Na}$ defesa da fundamentalidade dos direitos sociais, o constitucionalista italiano Luigi Ferrajoli associa a recusa à normatividade dos direitos sociais a uma confusão entre os conceitos de direitos e garantias. O autor rejeita concepções imperativistas do direito, a exemplo da fornecida por Hans Kelsen, baseada na centralidade da sanção ${ }^{5}$. Luigi Ferrajoli patrocina que os direitos fundamentais sociais estabelecidos pelas Constituições exigem quase sempre leis de atuação que estabeleçam as suas garantias, que não são produzidas simultaneamente aos próprios direitos garantidos, como ocorre com os direitos patrimoniais. Nos direitos sociais, não há concomitância necessária de direitos e deveres, o que não conduz à conclusão de que não existam direitos.

pre realizáveis em razão da limitação de recursos. Segundo o autor, os direitos sociais foram então remetidos à esfera programática, em virtude de não conterem as garantias frequentemente ministradas pelos instrumentos processuais de proteção aos direitos de liberdade. Nos sistemas jurídicos preponderava a ideia de que apenas os direitos de liberdade eram de aplicabilidade imediata, enquanto os direitos sociais possuíam aplicabilidade mediata, por via do legislador. Todavia, Paulo Bonavides acredita que os direitos sociais se tornaram tão justiciáveis quanto os direitos de liberdade, especialmente se levarmos em conta dispositivos que estabelecem a aplicação imediata dos direitos fundamentais, como acontece com a Constituição brasileira (Bonavides, 2011: 564-565).

5. Sobre a concepção imperativista do direito, Kelsen, Hans (1945), General Theory of Law and State, Cambridge: Harvard University Press.
A concepção imperativista kenseniana, critica Luigi Ferrajoli, contraria a própria premissa positivista, já que direitos fundamentais formalmente produzidos por atos válidos, porém desvestidos de garantias, seriam inexistentes. Assim, grande parte dos direitos sociais e quase todos os direitos humanos previstos por convenções internacionais não seriam direitos, apenas pelo fato de serem privados de garantias (Ferrajoli, 2015: 76-77).

Constituições que prevêem catálogos de direitos sociais refletem pactos comprometidos com reais transformações na qualidade de vidas de todos os indivíduos, especialmente dos mais vulneráveis. Não há como pensarmos em um Estado Constitucional sem a realização mínima dos direitos conducentes ao bem-estar social. A legitimidade do Estado contemporâneo envolve ações efetivas e positivas que promovam melhorias nas vidas dos cidadãos. Tal não é só um objetivo, mas um resultado preconizado pelas Cartas Constitucionais e declarações de direitos humanos.

A questão que passamos a debater é que a previsão dos direitos sociais em Constituições e o reconhecimento da sua normatividade são passos vitais, mas insuficientes, isoladamente, para a concretização da justiça social. Uma crítica é que não raro a constitucionalização de direitos pode se esgotar na produção de meros símbolos, desprovidos de efetividade ${ }^{6}$.

6. A este respeito, merece consideração a concepção de «constitucionalização simbólica» de Marcelo Neves. Esta designa normas constitucionais que representam meros símbolos, ou seja, textos constitucionais que são criados não para serem concretizados, mas para desempenhar uma função político-ideológica. Há uma sobreposição do sistema político em relação ao sistema jurídico. A função simbólica prepondera em detrimento da função instrumental normativa. A constituciona- 
Nos confrontamos com a dificuldade de concretização dos direitos sociais pela jurisdição na ausência de leis. Se não existe uma impossibilidade absoluta, estamos diante, ao menos, de uma robusta restrição prática. Os problemas envolvem a precariedade do acesso das pessoas vulneráveis à justiça e dificuldades orçamentárias dos Estados, mas não se limitam a eles. A questão fulcral, que evidentemente está ligada aos problemas descritos, é a primordialidade de políticas públicas que universalizem os direitos sociais cada vez mais.

$\mathrm{Na}$ defesa da plausibilidade dos direitos sociais, nos unimos à Amartya Sen, para quem a não realização de um direito não o transforma em um não direito, mas pede remédio, uma ação reparadora, uma ação social acrescida (Sen, 2009: 505).

Neste contexto, a teoria de Amartya Sen é especialmente importante para países em desenvolvimento, em que pensar em uma justiça transcendental pode se revelar um exercício puramente teórico, considerando as gritantes desigualdades econômicas e sociais existentes.

Atentos às particularidades e jusfundamentalidade dos direitos sociais, nossa atenção deve se dirigir, então, aos caminhos que podem ser trilhados para o aprimoramento da sua efetividade, o que é urgente, sobretudo nas comunidades políticas em desenvolvimento.

Miguel Nogueira de Brito, Tiago Fidalgo de Freitas e Jorge Silva Sampaio questionam se um Estado de bem-estar social depende da existência de direitos sociais constitucionais. A resposta, segundo os

lização simbólica apresenta uma baixa concretização do texto constitucional e oculta problemas sociais que impedem transformações efetivas na comunidade política. (Neves, 2011). autores, é negativa. Por um lado, eles lecionam não haver clareza se a existência de benefícios sociais subordina-se ao entrincheiramento constitucional dos direitos sociais. Mas, por outro lado, pontuam que seu entrincheiramento na Constituição não pode ser indiferente do ponto de vista jurídico (Brito et al.,2014: 01-07).

Endossamos a compreensão dos direitos sociais como normas jurídicas que devem ser concretizadas pelos Estados. Todavia, é possível que os remédios e os percursos adotados para efetivar os direitos de primeira «dimensão» ou "geração» não logrem êxito em relação aos direitos sociais.

Mirar os direitos sociais através de uma óptica que não seja estritamente liberal, individualista ou patrimonialista pode nos auxiliar na missão de expandir sua concretização. Propomos concebê-los à luz de uma visão solidária da sociedade. Não é porque o direito à liberdade reclama condições materiais existenciais mínimas que concluímos mecanicamente que os direitos sociais não são sujeitos a um regime e caracterização próprios. São direitos tão fundamentais quanto aqueles de primeira «geração», o que não quer dizer que não possuam particularidades.

O princípio rawlsiano da «diferença», ao focar nas dificuldades enfrentadas pelas pessoas mais carentes, evidencia a relevância da equidade para os arranjos sociais. Amartya Sen busca ir além. Nos provoca a progredir a qualidade de vida das pessoas por intermédio da efetiva avaliação das liberdades e capacidades humanas, desvinculando sua avaliação dos meios em si mesmos.

Com a expansão da ideia de justiça, temos um empenho conjunto que envolve uma escolha institucional, ajustamentos de comportamentos e procedimentos de 
correção dos arranjos sociais. Entretanto, Amartya Sen salienta a ação política por outras vias. A ampliação das capacidades pode implicar um maior poder de influenciar a vida das outras pessoas. Um indivíduo poderá encontrar boas razões para usar a ampliação de sua capacidade para se dedicar a engrandecer a vida dos demais, especialmente daqueles que vivem em condições relativamente piores do que as suas, ao invés de se concentrar unicamente em seu próprio bem-estar (Sen, 2009: 389).

Martha Nussbaum critica que a tradição do contrato social (em que John Rawls, por exemplo, se insere) não exige generosidade. Segundo a filósofa, a referida doutrina extrai princípios políticos a partir da ideia de vantagem mútua entre as pessoas, sem assumir que os seres humanos possuem laços profundos e motivacionalmente poderosos com os outros (Nussbaum, 2006: 408).

A abordagem das capacidades, aprofundada por Martha Nussbaum, auxilia na compreensão de uma visão solidária dos direitos sociais. Segundo a investigadora, uma ambiguidade na tradição dos direitos diz respeito à relação entre a primeira e a segunda "gerações de direitos». Ela questiona: as liberdades políticas e civis podem ser garantidas precedentemente e independentemente da proteção dos direitos sociais e econômicos? Acredita que é isto que sugere uma influente vertente na tradição da filosofia política liberal, assim como a recorrente distinção entre direitos de primeira e segunda «geração» no debate internacional acerca dos direitos humanos (Nussbaum, 2006: 288-290).

Em um primeiro momento, a teoria de justiça de John Rawls faz parte da referida tradição. Para Martha Nussbaum, isto pode ser percebido pela prioridade lexical que John Rawls atribui aos princípios econômicos, a despeito de também sustentar que em um estágio inferior do desenvolvimento econômico a recusa da igual liberdade possa ser aceita para elevar a qualidade da civilização de tal forma que no devido curso as liberdades iguais possam ser desfrutadas por todos (Martha Nussbaum, 2006: 294-295).

Ambas as afirmações rawlsianas, segundo a pesquisadora, sugerem fortemente a interdependência conceitual das duas esferas, e a prioridade léxica indica que após um certo estágio do desenvolvimento, a liberdade é causalmente independente da redistribuição econômica. É possível, entretanto, pensar diferente: pode-se acreditar que uma adequada consideração, por exemplo, da liberdade de expressão, envolve a discussão sobre a distribuição econômica (como o acesso à educação). Ainda que não se acredite na interdependência conceitual das duas esferas, é possível afirmar que a liberdade de expressão e a liberdade política possuem pré-requisitos materiais, mesmo em uma sociedade desenvolvida (Martha Nussbaum, 2006: 297-298).

A pensadora explica que é possível que às pessoas sem acesso suficiente à educação, ou com acesso desigual, não seja oferecido completamente o direito de liberdade de expressão, na medida em que pessoas analfabetas não exercerão o debate político em base de igualdade com as demais. Destarte, embora pensadores influentes dos direitos humanos enfatizem a interdependência entre as gerações de direitos, tal não foi totalmente incorporado nos documentos e nos raciocínios a seu respeito, que dependem da distinção entre as gerações (Martha Nussbaum, 2006: 301-302). 
Em Political Liberalism, Martha Nussbaum acredita que John Rawls parece atestar o ponto mencionado ao sugerir que o primeiro princípio, que abrange iguais liberdades básicas, possa ser precedido por uma prioridade lexical que impõe que as necessidades vitais dos cidadãos sejam atendidas, pelo menos na medida em que os indivíduos compreendam e sejam capazes de exercer fecundamente tais direitos e liberdades. Ainda que John Rawls não elabore os requisitos impostos pelo princípio, pelo menos reconhece a interdependência entre liberdade e fatores econômicos (Martha Nussbaum, 2006: 303-304)

Em uma perspectiva mais crítica e não inserida na tradicional lógica liberal, Joaquín Herrera Flores refuta uma divisão entre duas classes de direitos humanos: i) individuais; e ii) sociais, econômicos e culturais. Defende uma só classe de direitos para todas e todos: os direitos humanos. Acredita que a liberdade e a igualdade são, na verdade, duas faces da mesma moeda. Sem condições que as coloquem em prática, por intermédio de políticas de igualdade que concretizem os direitos sociais, econômicos e culturais, as liberdades individuais e os direitos sociais não têm espaço em nosso mundo. A liberdade deve ser garantida a todos os seres humanos, e, portanto, nosso desafio não é decifrar teoricamente quais direitos são mais importantes, mas compreender que, desde as suas origens, a luta pela dignidade se reveste de um caráter global, e não parcelado. A luta pela dignidade é um elemento ético e político universal que tem todas as pessoas e grupos humanos como beneficiários (Flores, 2009: 68-69).

Miguel Nogueira de Brito nos faz refletir que os direitos sociais tanto protegem quanto capacitam o cidadão. Sua propos- ta é compreender a associação dos direitos sociais ao pertencimento de seus titulares a uma comunidade política. Assim, considera fazer sentido questionarmos a relevância de uma dimensão política dos direitos sociais (Brito, 2013).

Pela perspectiva neoliberal, leciona o pesquisador, efetivas prestações sociais são um subproduto de uma economia capitalista que funcione bem e, tanto quanto possível, devem ser integrados em um sistema de caridade privada. Pela chamada perpectiva patrimonialista ou proprietária, os direitos sociais são tão imperativos quanto os direitos de propriedade e tão individualistas quanto estes (Brito, 2013)

Miguel Nogueira de Brito observa que em cada visão perdemos uma dimensão importante dos direitos sociais. A perspectiva neoliberal ignora a clara questão de que os direitos socias são uma questão de justiça, não de caridade. Já a visão patrimonialista perde a dimensão da solidariedade dos direitos sociais (Brito, 2013).

Segundo o autor, as duas visões formam os dois lados da mesma moeda. Trata-se da moeda da primazia da vida econômica sobre todas as outras dimensões da vida social. Propõe, então, explorarmos a dimensão política dos direitos sociais em face da visão que centra o aprimoramento de sua proteção através de uma judicialização assertiva (Brito, 2013).

Uma particular indagação do autor nos leva a evoluirmos na investigação dos direitos sociais através de um horizonte atento às suas particularidades, sem perdermos de vista a indivisibilidade dos direitos humanos. Trata-se do questionamento acerca da natureza jurídico-constitucional de um direito ao mínimo necessário para a substistência humana. A resposta à questão depende da concep- 
ção do referido direito. Miguel Nogueira de Brito identifica duas visões acerca da natureza do direito ao mínimo de existência: i) como a garantia de conteúdo mínimo dos direitos sociais; ou ii) como a formulação de um princípio de realização de um mínimo social enquanto instrumento de concretização dos direitos sociais na sua dimensão de direitos prestacionais (Brito, 2014, b: 1123-1124).

$\mathrm{O}$ autor leciona que para a primeira visão, o direito ao mínimo de existência pode ser compreendido como algo próximo de um direito de liberdade, uma vez que os direitos sociais assumem através dele traços próprios dos direitos, liberdades e garantias do respectivo regime. Já para a segunda, pode ser concebido como um instrumento de concretização da dimensão positiva dos direitos sociais (Brito, idem).

A compreensão do direito ao mínimo de subsistência como pressuposto dos direitos de liberdade ou como distintos da lógica subjacente aos direitos clássicos, segundo o pesquisador, é também de índole filosófica e envolve o estatuto que for conferido ao direito de propriedade como fundamental. Este direito ocupa uma posição especial no sistema de direitos fundamentais, uma vez que associa ao seu conteúdo econômico, de direito sobre recursos materiais, uma dimensão negativa incontestável (Brito, idem).

A questão que Miguel Nogueira de Brito expõe é não ser pensável um direito de propriedade desconexo de um direito a um mínimo social no contexto de uma ordem patrimonial privada que se pretenda legítima. Assim, o direito a um mínimo de subsistência não é um simples pressuposto do exercício dos direitos de liberdade, mas antes uma condição da própria legitimidade de alguns desses direitos e, nessa medida, parte irrenunciável de um sistema complexo de direitos fundamentais (Brito, idem).

Dos escritos dos autores discutidos, extraímos que o progresso da efetividade dos direitos sociais envolve a adoção de outras lentes: que nos permitam enxergar a possibilidade de confluência de esforços em sua implementação e a relação entre liberdades e igualdades em uma teoria integradora dos direitos humanos. Neste sentido, a consciência e o empenhamento de cada um dos indivíduos podem influenciar muitas vidas.

Embora existam caminhos não dependentes do Estado e da legislação, o desenvolvimento de boas políticas públicas e a elaboração de leis não devem ser relegados no desafio que é a construção de um Estado Constitucional Social. Evidenciam atuações que destacam a importância de instituições justas e são também alternativas à judicialização, na medida em que envolvem a edição de políticas que universalizem os direitos sociais.

As análises de Amartya Sen e Martha Nussbaum a respeito da importância do empoderamento de todos os membros da sociedade, para que ajam politica e socialmente para além das vias do Estado e da lei, não põem em causa a imprescindibilidade das instituições. Estas devem cumprir o seu papel constitucional de garantia da expansão das capacidades humanas. As duas ações podem e devem trilhar, juntas, o caminho da realização dos direitos sociais, e consequemente, das capacidades da pessoa humana.

A dimensão política dos direitos sociais a que se refere Nogueira de Brito nos convida também a explorar a evolução de sua proteção. Enquanto direitos que se associam ao pertencimento de seus titulares 
a uma comunidade política, sem pôr em causa a indivisibilidade e integração dos direitos humanos, é essencial que sejam refletidos de forma especial, de modo que as diversas dimensões da vida social não sejam eclipsadas pela vida econômica.

Uma visão meramente liberal dos direitos sociais é deficitária. A efetividade dos direitos sociais requer muito mais do que a sua positivação. Nossa missão é progredir na investigação de sua natureza com o fito de auxiliarmos na tarefa da sua concretização, em que cada indivíduo pode exercer o protagonismo na reparação de muitas injustiças sociais.

Talvez seja necessário irmos além das teorias tradicionais liberais dos direitos humanos. Uma abordagem crítica e contextualizada dos direitos humanos pode nos fornecer preciosas contribuições. É o que elucidam os escritos de Joaquín Herrera Flores a respeito da própria crítica do conhecimento. O autor objeta uma universalização dos direitos impregnada por uma espécie imperialista de conhecimento, em que se parte de uma relação imperialista entre "nós" e os "outros", de modo a impor uma ordem fechada que reproduza tal situação de subordinação. Sua proposta é rompermos com a compreensão do "outro" como objeto de manipulação do colonizador. No seu horizonte, a versão imperialista-colonizadora do conhecimento deve ceder espaço a um conhecimento democrático-emancipador, que tenha como finalidade implantar relações de solidariedade entre "nós" e os "outros", isto é, em que os "outros" sejam considerados tão sujeitos de conhecimento quanto "nós" mesmos (Flores, 2009: 102).

Para Joaquín Herrera Flores, a racionalidade que está na base da ideologia jurí- dica e política hegemônica, neoliberal e neoconservadora, justifica o descumprimento dos direitos humanos. Para tanto, recorre a indicadores que prescrevem a primazia das liberdades individuais e o Estado formal de direito acima dos direitos sociais e do Estado social de direito (Flores, 2009: 92).

O pensador contrapõe a proposta de John Rawls de colocar de lado, sob o hipotético «véu da ignorância», o que somos e o que possuímos. Acredita que a teoria rawlsiana limita a defesa de direitos aos chamados «bens primários», ou seja, àqueles direitos individuais. Para o autor, John Rawls considera a liberdade um valor separado e hierarquicamente superior à igualdade. Joaquín Herrera Flores teme a entrega de direitos à iniciativa privada, livre de qualquer impedimento institucional e social. Rejeita a pureza de uma teoria acobertada por um «véu da ignorância» e propõe que apenas o impuro, o contaminado de contexto, de diferenças, e mestiçagens, pode ser objeto de nossos conhecimentos (Flores, 2009: 79-80).

\section{Conclusões}

1. A teoria de Amartya Sen aborda a questão da justiça social com um enfoque diverso dos escritos de John Rawls e Ronald Dworkin. Com a perspectiva centrada nas realizações sociais, Amartya Sen busca se afastar da ideia transcendental de justiça. O autor não acredita que consensos baseados na ideia de contratos sociais consistam em pontos de partida ou de chegada adequados de uma boa teoria da justiça. Sem embargo das críticas lançadas, há pontos de proximidade e complementariedade entre as teorias, 
especialmente de John Rawls e Amartya Sen;

2. Amartya Sen desloca a atenção de hipotéticos princípios regentes de sociedade idealmente justas e dos «bens primários» rawlsianos. Se concentra nas muitas injustiças reais e desacordos sobre arranjos ideais. Esteado em lições budistas, defende uma base solidária para as interações e motivações humanas;

3. Na abordagem da justiça como capacidades, Amartya Sen patrocina que a expansão das liberdades das pessoas é o principal meio e o principal fim do desenvolvimento. Em um mundo cheio de privações e profundas desigualdades sociais, muitas vidas humanas são prejudicadas, devendo ser as principais destinatárias das ações sobre a justiça;

4. À luz da teoria de Amartya Sen, os direitos sociais são direitos humanos imprescindíveis à expansão das capacidades. Não são dependentes da nacionalidade das pessoas ou de contratos sociais. Também não podem ser considerados inexistentes ou negligenciáveis em virtude da falta de especificação em textos constitucionais ou legais. Impõem efetivas obrigações não apenas aos Estados, mas à humanidade como um todo. Há uma pluralidade de ações que contribuem para a efetividade dos direitos sociais;

5. O horizonte de Amartya Sen contribui para a investigação acerca da natureza e especificidades dos direitos sociais, mas deixa espaço aberto para que aprofundemos a análise. Avançamos na questão relativa a em que medida os direitos sociais são direitos humanos e constitucionais fundamentais. As abordagens de Martha Nussbaum,
Miguel Nogueira de Brito e Joaquín Herrera Flores descortinam uma dimensão política e solidária dos direitos sociais como uma possibilidade para a sua efetividade, atualmente dependente de um processo exclusivamente de judicialização. A positivação dos direitos sociais nas Constituições e legislações, embora muito importante, não supre a luta política, social e jurídica paralela dos indivíduos, entidades civis, ONGs, instituições políticas e de todos os comprometidos com a concretização daqueles direitos mais vitais ao efetivo pertencimento dos cidadãos à comunidade global; e

6. Uma teoria crítica e contextualizada dos direitos humanos, a exemplo da fornecida por Joaquín Herrera Flores, viabiliza uma perspectiva democrático-emancipadora desde a produção do conhecimento. Busca não a pureza axiológica ou a prevalência da liberdade quanto à igualdade, mas a efetiva produção de um Estado Constitucional Social que crie condições para a realização da dignidade da vida humana.

\section{Referências}

Bonavides, Paulo (2011), Curso de Direito Constitucional, São Paulo: Editora Malheiros.

Brito, Miguel Nogueira de (2013), "Are Social Rights More Like Civil or Political Rights?", Apresentação na Conferência do Instituto de Ciências Sociais da Universidade de Lisboa de 2013. Disponível em https://www.ulisboa.pt/wp-content/uploads/ Programa-Completo-e-Resumos.pdf [14 de maio de 2019].

(2014a), "O ordenamento constitucional português e a garantia de um nível mínimo de substistência", in Antu- 
nes, Maria [coord.], Estudos em memória do Conselheiro Artur Maurício, Coimbra: Coimbra Editora.

et al (2014b), "Social Rights and the 70th anniversary of the Second Bill of Rights", in Revista Eletrónica de Direito Público, vol. 1, núm. 3, Lisboa (Dez. 2014). Disponível em: http://www.e-publica.pt/volumes/v1n3a01.html [14 de maio de 2019].

Cohen, Gerald Allan (1993), "Amartya Sen's unequal world", in Economic and Political Weekly, vol. 28, núm. 40, Mumbai (Out. 1993).

Dworkin, Ronald (2005), A Virtude Soberana: A Teoria e a Prática da Igualdade, traduzido por Jussara Simões, São Paulo: Editora Martins Fontes. (2006), Is Democracy Possible Here? Principles for a New Political Debate, Cambridge: Harvard University Press.

Ferrajoli, Luigi (2015), A democracia através dos Direitos, traduzido por Dias, Jefferson Aparecido et al., São Paulo: Revista dos Tribunais.

Herrera, Joaquín (2009), A reinvenção dos direitos humanos, traduzido por Sousa, Alexandre Araujo de et al., Florianópolis: Fundação Boiteux.

Kelsen, Hans (1945), General Theory of Law and State, Cambridge: Harvard University Press.

(2011), Creating Capabilities: The Humam Development Approach, Cambridge: Belknap Press.

Marin, Solange Regina e Quintana, André Marzulo (2012), "Amartya Sen e a escolha social: uma extensão da teoria da justiça de John Rawls?", in Revista de Economia Contemporânea, vol. 16, núm. 3, Rio de Janeiro (Set./Dez. 2012).

Neves, Marcelo (2011), Constitucionalização Simbólica, São Paulo: Editora Martins Fontes.
Novais, Jorge Reis (2017), Direitos sociais: teoria jurídica dos direitos sociais enquanto direitos fundamentais, Lisboa: Editora Associação Académica da Faculdade de Direito da Universidade de Lisboa.

Nussbaum, Martha (2006), Frontiers of Justice: Disability, Nationality, Species Membership, Cambridge: Belknap Press.

Pansieri, Flávio (2016), "A crítica de Amartya Sen à concepção rawlsiana de justiça", in Revista Sequência - Estudos Jurídicos e Políticos, vol. 37, núm. 74, Florianópolis (Dez. 2016).

Rawls, John (1993), Uma Teoria da Justiça, traduzido por Carlos Pinto Correia, Lisboa: Editora Fundamentos. (1997), O Pluralismo Político, traduzido por João Sedas Nunes, Lisboa: Editora Presença. (2001), Justice as Fairness: A Restatment, Erin Kelly [coord], Cambridge: Harvard University Press.

Sarlet, Ingo (2007), A Eficácia dos Direitos Fundamentais, Porto Alegre: Editora Livraria do Advogado.

Sen, Amartya (2000), Desenvolvimento como Liberdade, traduzido por Motta, Laura Teixeira, São Paulo: Editora Companhia das Letras.

(2012), A Ideia de Justiça, traduzido por Basto, Nuno Castello-Branco, Lisboa: Editora Almedina. 